\title{
An Autopsy Case of Cytokeratin 7-positive Minute Adenocarcinoma of the Lung with Systemic Metastases
}

\author{
Yumi Ise, Hiroaki Yanagawa, Takanori Hirose*, Kenji Tani, Seiji Yano, Yoshihiro Suzuki, \\ Eiji Takeuchi, Kouji Maniwa, Eiji Shimizu, Fumitaka Ogushi, Toshiaki Sano* and Saburo Sone
}

We describe a 60-year-old woman with leg pain. Although metastatic bone tumor and atypical cells mimicking signet-ring cells in the bone marrow picture were observed, systemic survey revealed no primary lesion. The patient died two months after admission from systemic progress of the disease. Autopsy revealed a small focus of adenocarcinoma within the right upper lobe of the lung and systemic metastases without any particular changes in the gastrointestinal tract. The tumor cells of the lung were diffusely positive for cytokeratin 7 , whereas cytokeratin 20 immunoreactivity was weak and focal, and that supported the lung origin of the present tumor. Moreover, the tumor cells in the bone marrow showed a similar pattern in immunoreactivity. These findings suggest that cytokeratin 7 and cytokeratin 20 immunoreactivity is helpful for the premorten diagnosis of the metastatic tumor of unknown origin.

(Internal Medicine 37: 766-769, 1998)

Key words: signet-ring cell carcinoma, immunohistochemistry, metastatic bone tumor

\section{Introduction}

Bone metastases are often the first manifestation of malignant diseases. Lung adenocarcinoma and uterine adenocarcinoma are reported to be the major primary site (1). However, in some cases the primary site of the bone metastases cannot be identified by systemic examination.

In the present paper, we describe a female patient with signet-ring cell-like adenocarcinoma of uncertain origin, which was found in the bone marrow picture. The autopsy findings and immunohistochemical analysis are also described.

\section{Case Report}

A 60-year-old woman was seen by a local physician with pain in her right lower extremity in February 1997. The patient had no evidence of occupational contaminants. For further examination, she was then referred to Tokushima University Hospital. On admission, she complained of pain in the right lower extremity without systemic pain. No cervical, axillar or inguinal lymph nodes were palpable, and physical examination revealed no remarkable findings. Laboratory examination was as follows: hemoglobin $10.9 \mathrm{~g} / \mathrm{dl}$, white blood cell count $5,100 /$ $\mu \mathrm{l}$ with $50 \%$ neutrophils, $4 \%$ monocytes, $43 \%$ lymphocytes, platelet $15.3 \times 10^{4} / \mu 1$, aspartate aminotransferase $18 \mathrm{U} / l$, alanine aminotransferase $15 \mathrm{IU} / l$, lactate dehydrogenase $381 \mathrm{U} / l$, alkaline phosphatase 4,560 IU/l, $\gamma$-glutamyl transpeptidase $23 \mathrm{U} / l$, amylase $48 \mathrm{U} / l$, total protein $6.7 \mathrm{~g} / \mathrm{dl}$, albumin $3.7 \mathrm{~g} / \mathrm{dl}$, creatinine $0.6 \mathrm{mg} / \mathrm{dl}$, Na $142 \mathrm{mEq} / \mathrm{l}$, K $3.9 \mathrm{mEq} / \mathrm{l}$, Ca $8.3 \mathrm{mg} / \mathrm{dl}$, erythrocyte sedimentation rate $26 \mathrm{~mm} / \mathrm{h}$, C-reactive protein $1.75 \mathrm{mg} / \mathrm{dl}$. Serum tumor marker levels (normal range in parentheses) were as follows: squamous cell carcinoma-related antigen $0.79 \mathrm{ng} / \mathrm{ml}(<1.5)$, carcinoembryonic antigen $2.0 \mathrm{ng} / \mathrm{ml}$ $(<5.0)$, carbohydrate antigen $19-929 \mathrm{U} / \mathrm{ml}(<47)$, carbohydrate antigen $12514 \mathrm{U} / \mathrm{ml}(<42)$ and neuron-specific enolase $5.9 \mathrm{ng} /$ $\mathrm{ml}(<10)$.

Osteolytic change was observed in the right fibula and bone scintigram revealed multiple abnormal accumulations (Fig. 1). The patient was diagnosed as having metastatic bone tumor, and we performed systemic survey for the detection of the primary site. A small nodule in upper lobe of the right lung was observed in the chest computed tomography (CT) scan (Fig. 2). Examination with fiberoptic bronchoscope revealed no endoscopic findings and no malignant cells were obtained. Gastrointestinal examination, including endoscopy, and upper and lower barium series revealed no abnormal findings. No abnormal findings were observed in brain magnetic resonance imaging, cervical ultrasonogram, breast examination by a sur-

From the Third Department of Internal Medicine and *the First Department of Pathology, the University of Tokushima School of Medicine, Tokushima Received for publication October 6, 1997; Accepted for publication June 29, 1998

Reprint requests should be addressed to Dr. Hiroaki Yanagawa, the Third Department of Internal Medicine, the University of Tokushima School of Medicine, 3 Kuramoto-cho, Tokushima 770-8503 
geon, abdominal CT or gynecological examination. Bone marrow picture demonstrated the presence of a small amount of atypical cells mimicking signet-ring cells (Fig. 3).

Although the primary site was unknown, the patient was

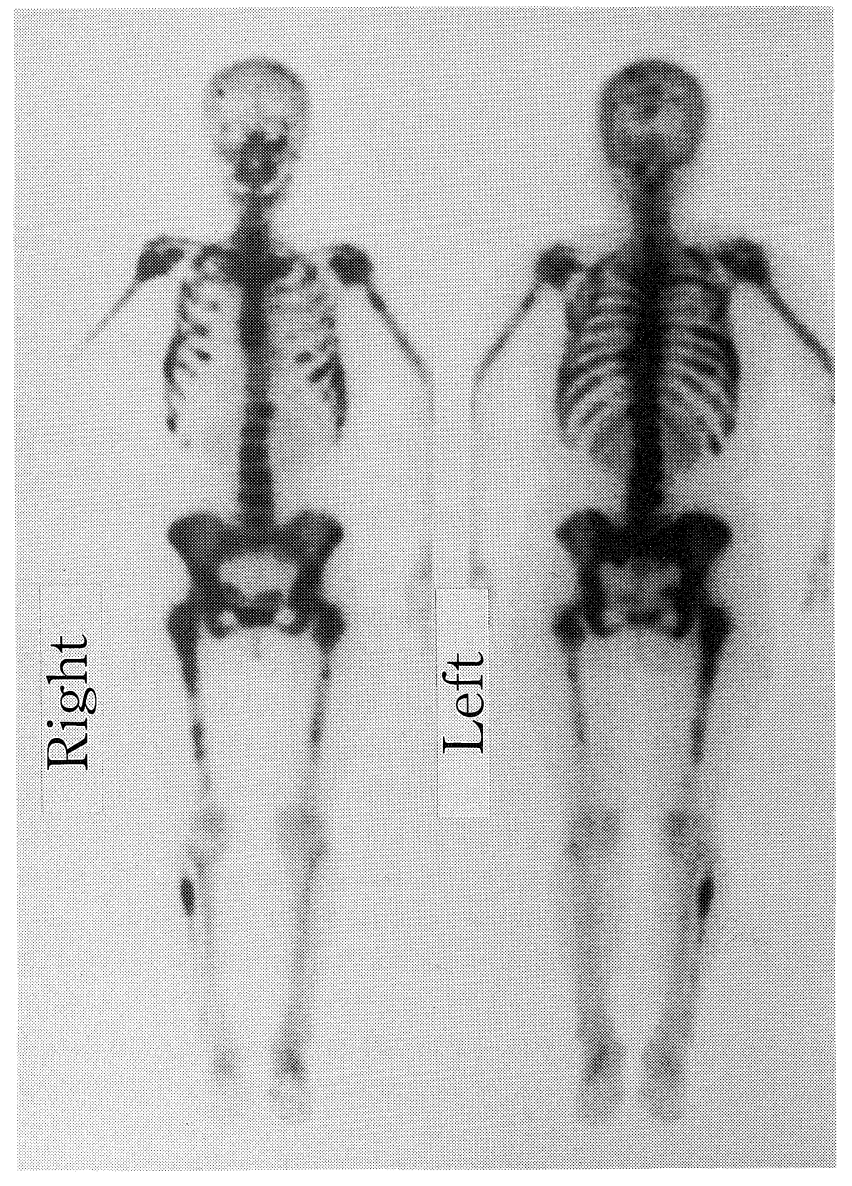

Figure 1. Bone scintigram, revealing multiple abnormal accumulations.

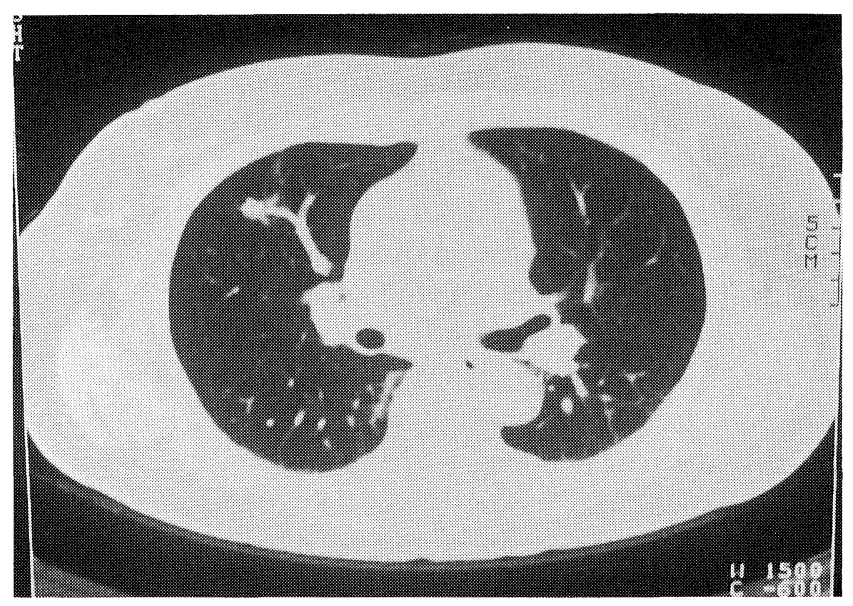

Figure 2. Chest CT scan on admission. A small nodule in upper lobe of the right lung was seen. diagnosed as having adenocarcinoma with bone marrow invasion. Then she was treated with oral medication of $600 \mathrm{mg} / \mathrm{day}$ of tegafur with uracil (UFT), but it was discontinued due to gastrointestinal side effects. Palliative therapy with medication of morphine hydrochloride and non-steroidal anti-inflammatory drugs was effective for relief of the pain, but the disease progressed and the patient died from complicated disseminated intravascular coagulation on April 26, 1997.

Postmortem examination was performed. A small, ill-defined nodule, $1.2 \times 0.9 \mathrm{~cm}$ in diameter, was identified in the upper lobe of the right lung. Microscopic examination revealed that the lesion was well-differentiated adenocarcinoma composed of mucin-containing tumor cells, which were identical to those found in the bone marrow picture (Fig. 4). Immunohistochemically, most tumor cells were strongly positive for cytokeratin 7 (Dako) (Fig. 5), while cytokeratin 20 (Dako)

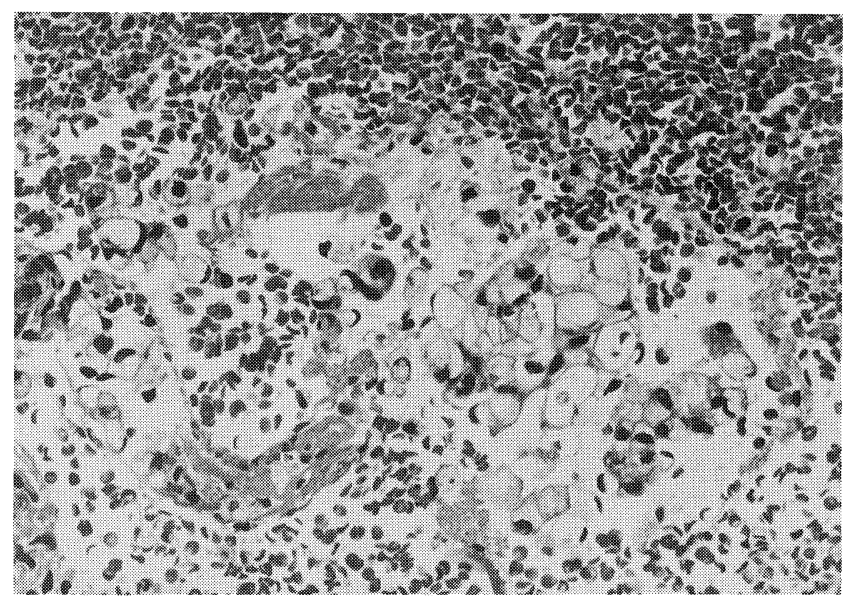

Figure 3. Bone marrow picture, showing small aggregation of atypical tumor cells of signet-ring cell type (HE stain, $\times 380)$.

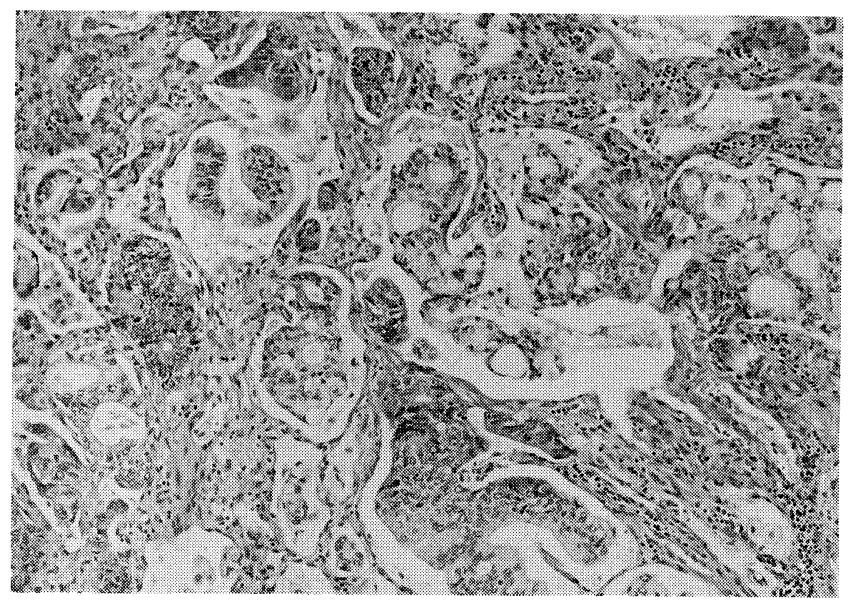

Figure 4. Microscopic examination of the small nodule in the upper lobe of the right lung by postmortem examination. Mucincontaining tumor cells, often mimicking signet-ring cells, exhibit tubular and papillary patterns (HE stain, $\times 127)$. 


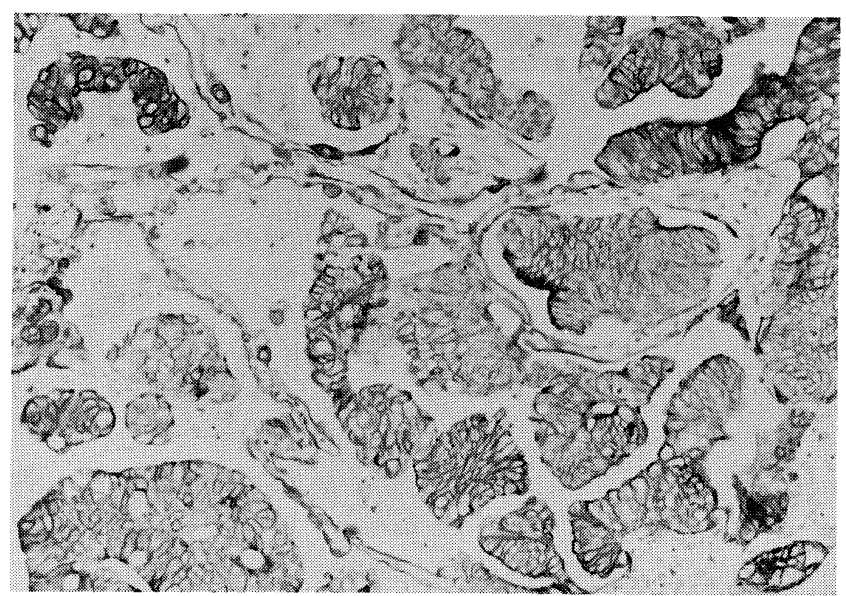

Figure 5. Immunohistochemistry of the lung tumor. The tumor cells are positively stained by cytokeratin 7 (Dako). (labeled by the streptavidin biotin method, $\times 190$ ).

immunoreactivity was focal and weak. Numerous tumor emboli in the small vessels of the bilateral lungs, and systemic metastases to bone marrow, liver spleen and kidney were observed. The tumor cells in the bone marrow also showed strong reactivity for cytokeratin 7 (Dako) (Fig. 6), while cytokeratin 20 (Dako) immunoreactivity was weak. No particular changes were seen in the stomach, pancreas, rectum, urinary bladder, or small and large intestine.

\section{Discussion}

Bone metastases are often the first manifestation of malignant diseases. Baron et al (1) examined 29 cases whose first sign of a tumor was a bone metastasis, and reported that lung adenocarcinoma and uterine adenocarcinoma were the major primary site. But, in some cases, the primary site of the bone metastases cannot be identified by systemic examination. Nakano et al (2) also examined 20 patients whose initial manifestation was bone metastasis, and reported that the primary site had not been detected within two months after presentation in three cases among these 20 patients. Lung cancer had been recognized by follow-up study in two of three cases, and autopsy revealed adrenal cancer in one case.

In the present case, a small nodule in upper lobe of the right lung was observed in chest CT scan and we performed examination with fiberoptic bronchoscope, but we obtained no endoscopic findings and no malignant cells in the specimen. On the other hand, we observed aggregation of signet ring-like atypical cells in the bone marrow picture. Signet-ring cell carcinomas have been found in a variety of organs, such as stomach, colon and breast, but primary lung adenocarcinoma with signet-ring cells is rare (3). Therefore, undetectable minute tumor in the gastrointestinal tract, as well as a small nodule in upper lobe of the right lung, was suspected as the primary site by premortem examination.

Postmortem examination revealed a small adenocarcinoma

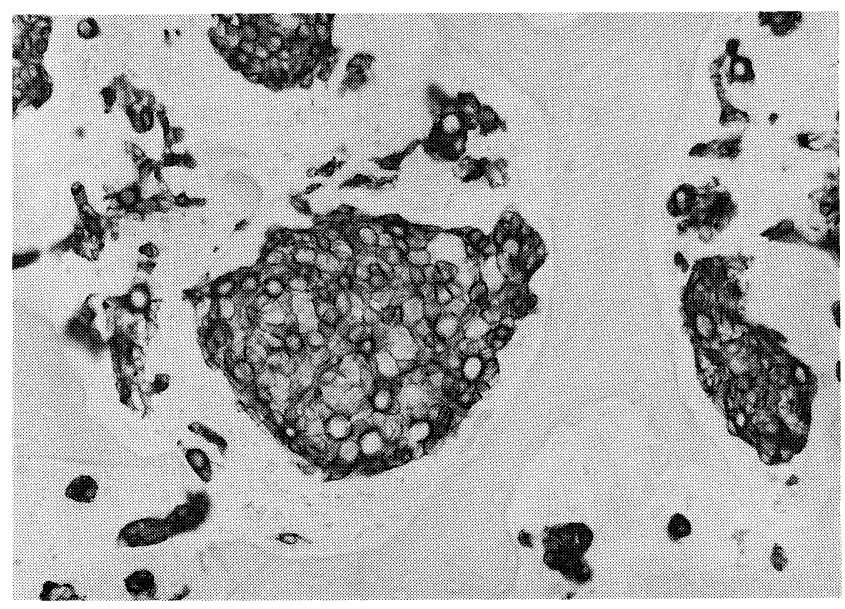

Figure 6. Immunohistochemistry of the tumor cells in the bone marrow. The tumor cells are positively stained by cytokeratin 7 (Dako). (labeled by the streptavidin biotin method, $\times 150$ ).

in the lung. To evaluate whether the lung tumor is metastatic or primary, we performed immunohistochemical analysis. The cytokeratins are a family of $40 \mathrm{kD}$ to $70 \mathrm{kD}$ intermediate filament proteins that are widely distributed in epithelial cells (4), and they are cataloged under the numbers 1 through 20 by Moll et al (5). Among the cytokeratins, cytokeratin 7 is expressed in specific subtypes of adenocarcinoma from ovary, breast and lung, whereas carcinomas from the gastrointestinal tract are found to remain negative (6-8). On the other hand, cytokeratin 20 is expressed on various adenocarcinoma, including colorectal carcinoma, adenocarcinomas of the gallbladder and bile ducts, and ductal cell adenocarcinoma of the pancreas, but is not expressed on lung carcinoma (9). Moreover, Loy and Calaluce (10) examined 151 cases with adenocarcinoma and reported that the immunophenotype of cytokeratin 7 positive/ cytokeratin 20 negative was seen in $86 \%$ of pulmonary adenocarcinomas and $0 \%$ of colonic adenocarcinomas. Therefore, the cytokeratin 7 predominant pattern of the present case supported the diagnosis of pulmonary adenocarcinoma. We could not perform immunohistochemical analysis of the bone marrow specimen on premortem examination, but the postmortem examination revealed that tumor cells in the bone marrow also showed the immunophenotype of cytokeratin 7 positive/ cytokeratin 20 negative (Fig. 6). Therefore, premortem immunohistochemical examination of the tumor cells in the bone marrow might have been helpful for the diagnosis of the primary site in the present case.

In the present paper, we describe a female patient with signet-ring cell like adenocarcinoma of uncertain origin, who was diagnosed as pulmonary adenocarcinoma by postmortem examination. These findings suggest that immunohistochemical examinations of adenocarcinomas of uncertain origin with cytokeratin antibodies could be helpful for the premortem diagnosis of the primary site. 


\section{Cytokeratin 7-positive Lung Adenocarcinoma}

\section{References}

1) Baron MG, de la Gandara I, Espinosa E, de Paredes ML, Zamora P, Mondejar JL. Bone metastases as the first manifestation of a tumour. Int Orthop 15: 373-376, 1991.

2) Nakano $S$, Hasegawa $Y$, Ibuka $K$, et al. Survey for primary tumor site in patients with initial clinical presentation of bone metastasis. Kaku Igaku 30: 1049-1054, 1993 (in Japanese).

3) Kish JK, Ro JY, Ayala AG, McMurtrey MJ. Primary mucinous adenocarcinoma of the lung with signet-ring cells: a histochemical comparison with signet-ring cell carcinomas of other sites. Hum Pathol 20: 10971102, 1989.

4) Eichner R, Bonitz P, Sun TT. Classification of epidermal keratins according to their immunoreactivity, isoelectric point, and mode of expression. J Cell Biol 98: 1388-1396, 1984.

5) Moll R, Franke WW, Schiller DL, Geiger B, Krepler R. The catalog of human cytokeratins: patterns of expression in normal epithelia, tumors and cultured cells. Cell 31: 11-24, 1982.

6) Ramaekers F, van Niekerk C, Poels L, et al. Use of monoclonal antibodies to keratin 7 in the differential diagnosis of adenocarcinomas. Am J Pathol 136: 641-655, 1990.

7) van Niekerk CC, Boerman OC, Ramaekers FCS, Poels LG. Marker profile of different phases on the transition of normal human ovarian epithelium to ovarian carcinomas. Am J Pathol 138: 455-463, 1991.

8) van de Molengraft FJJM, van Niekerk CC, Jap PHK, Poels LG. OV-TL $12 / 30$ (keratin 7 antibody) is a marker of glandular differentiation in lung cancer. Histopathology 22: 35-38, 1993.

9) Moll R, Löwe A, Laufer J, Franke WW. Cytokeratin 20 in human carcinomas. A new histodiagnostic marker detected by monoclonal antibodies. Am J Pathol 140: 427-447, 1992.

10) Loy TS, Calaluce RD. Utility of cytokeratin immunostaining in separating pulmonary adenocarcinomas from colonic adenocarcinomas. Am J Clin Pathol 102: 764-767, 1994. 